\title{
Limb amputation secondary to pseudoamniotic band syndrome after selective fetoscopic laser photocoagulation: case report
}

\author{
Soraia S. Cunha*, Rosália S. Coutada, Ana R. Neiva, Domingos C. Ribeiro
}

Department of Obstetrics and Gynecology, Unidade Local de Saúde do Alto Minho, Viana do Castelo, Portugal

Received: 08 September 2018

Accepted: 05 October 2018

\section{*Correspondence:}

Dr. Soraia S. Cunha,

E-mail: soraiacunha@hotmail.com

Copyright: (C) the author(s), publisher and licensee Medip Academy. This is an open-access article distributed under the terms of the Creative Commons Attribution Non-Commercial License, which permits unrestricted non-commercial use, distribution, and reproduction in any medium, provided the original work is properly cited.

\begin{abstract}
Pseudoamniotic band syndrome (PABS) is a rare iatrogenic complication that occurs after invasive procedures in monochorionic twins for treatment of twin-twin transfusion syndrome (TTTS). Selective fetoscopic laser photocoagulation (SFLP) is a commonly performed procedure for the treatment of severe TTTS that may lead to complications such as preterm labor, preterm rupture of membranes, cerebral lesions and fetal death. PABS has been reported to occur in up to $3 \%$ of cases of TTTS treated with laser, leading to limb abnormalities. There are no identifiable risk factors and antenatal detection of PABS is rare, but possible. Thus, obstetricians should be aware of this possibility in pregnancies treated by laser therapy for TTTS. The authors report a case of a monochorionic biamniotic twin pregnancy submitted to SFLP for TTTS at 19 weeks of gestation with postnatal diagnosis of PABS, presenting with amputation of a fetal limb.
\end{abstract}

Keywords: Fetoscopic laser surgery, Limb amputation, Pseudoamniotic band syndrome, Twin-twin transfusion syndrome

\section{INTRODUCTION}

Pseudoamniotic band syndrome (PABS) is a rare iatrogenic complication of invasive antenatal procedures, such as amniorreduction, septostomy, fetoscopic laser photocoagulation and bipolar cord coagulation in monochorionic twin-twin transfusion syndrome (TTTS). ${ }^{1-}$ 5 The reported incidence is $1.8-3.3 \%$ after invasive procedures. ${ }^{1-3}$

Selective fetoscopic laser photocoagulation (SFLP) of twin anastomoses on the chorionic plate has proved to improve survival in severe TTTS and is now offered widely as the first line treatment for severe TTTS presenting before 26 weeks of gestation.

Although preterm labor, preterm rupture of membranes, cerebral damage and fetal death are well-known adverse effects, PABS leading to limb abnormalities may also happen. The pathophysiologic mechanism of PABS is based on two hypotheses: inadvertent septostomy during invasive procedure and postoperative chorioamniotic membrane separation. ${ }^{1-3}$

Regardless of the mechanism, it can cause umbilical cord compression in a constrictive sheet or detachment of the ruptured amniotic membrane, with a risk of fetal limb constriction or amputation, facial cleft and even intrauterine death when the umbilical cord is involved. ${ }^{1-4}$ Few data are available concerning PABS.

To our knowledge, only 27 cases had been reported and fetal limbs were involved in 15 cases, leading to constriction or amputation. ${ }^{3}$

Authors report one additional PABS case in monochorionic twin pregnancy with amputation of a fetal limb, enhancing the importance of antenatal surveillance of the fetal limbs and umbilical cord after invasive inutero therapy. 


\section{CASE REPORT}

A 34-years-old woman, gravida 2, para 1, was referred to our Maternal-Fetal Unit at 9 weeks of gestation for spontaneous monochorionic biamniotic twin pregnancy. At 12 weeks of gestation, twins presented slightly discordant crown-rump lengths, but concordant amniotic fluid indexes with nuchal translucencies of 1.18 and 0.76 $\mathrm{mm}$ and normal Ductus Venosus. An ultrasound performed at 17 weeks of gestation revealed Quintero stage II TTTS.

After counseling, parents decided to submit to SFLP of vascular anastomosis. The procedure took place at 19 weeks in a referral center and no complications were noticed. Before the procedure, a normal morphology of the twins was confirmed.

In postoperative surveillance, no signs of recurrent TTTS were noticed and no fetal morphologic abnormalities were detected. Subsequent sonographic examinations revealed growth restriction of the donor, with concordant fluid indexes and normal umbilical artery flows.

At 27 weeks of gestation, pregnancy was complicated with a preterm rupture of membranes. A cesarean section was decided at 29 weeks and 6 days of gestation for severe growth restriction with abnormal flow in the umbilical artery.

A $1125 \mathrm{~g}$ girl (recipient) with Apgar scores at 1st and 5th minutes of 8/9 and a 475g girl (donor) with Apgar scores at 1 st and 5 th minutes of $6 / 8$ were delivered. After birth, physical examination showed amputation of the left hand of the donor with necrotic stumps of left-hand fingers still attached to the arm (Figure 1).

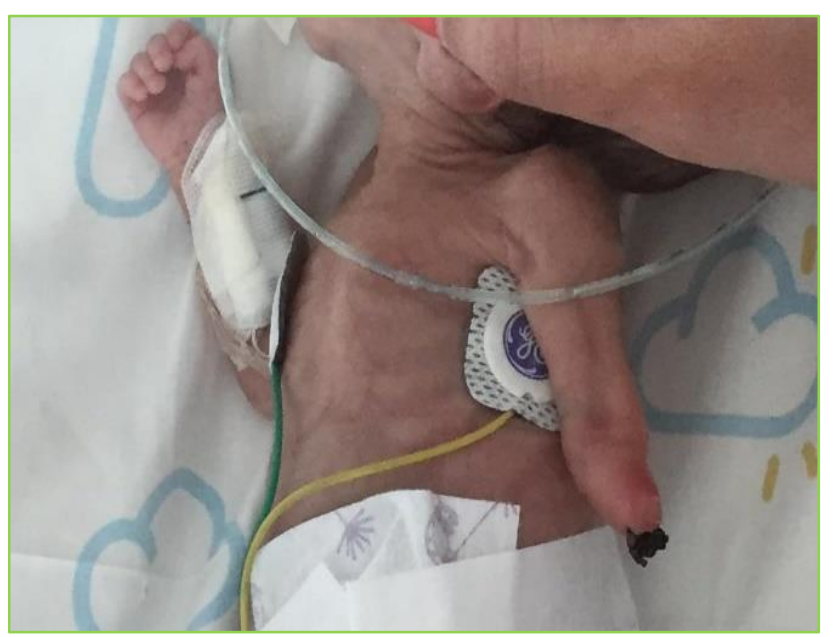

Figure 1: Amputation of the left hand with necrotic stumps of left-hand fingers still attached to the arm.

This amputation was attributed to PABS. The recipient twin showed no abnormalities. A bionic reconstruction of the affected hand is being attempted and functional recovery is expected.

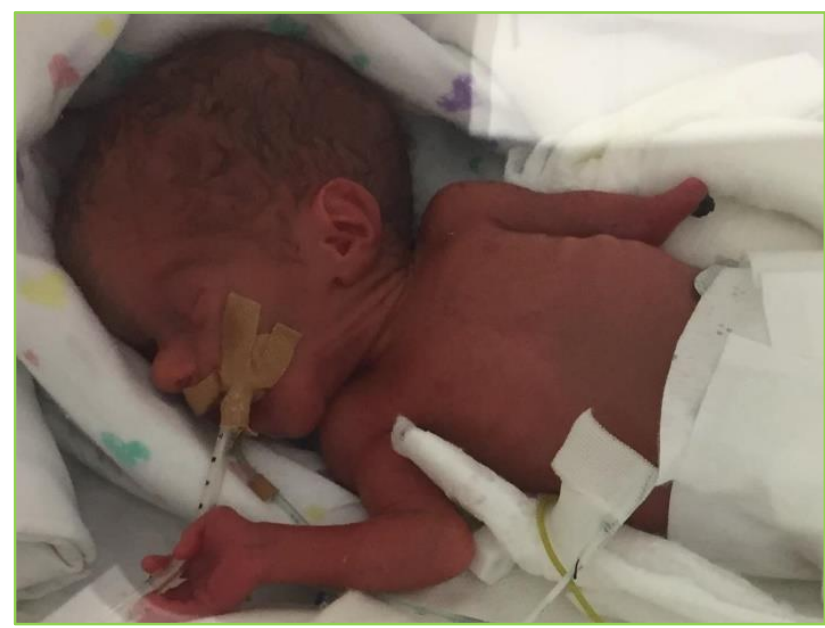

Figure 2: Another view of the affected limb.

\section{DISCUSSION}

TTTS is a complication affecting $6-15 \%$ of all monochorionic twin pregnancies and, with expectant management, is associated with a mortality rate of about $80-100 \% .^{2,6}$

It is defined sonographically by the combined presence of polydramnios in one sac and oligohydramnios in the other. Chronic imbalance in net flow between intertwin placental anastomoses are the basis for the onset of TTTS. Fist line treatment of severe TTTS is SFLP of placental intertwin anastomoses, which is associated with survival rates of at least one twin ranging from $75-85 \% .^{6,7}$

However, as with any invasive fetal procedure, laser therapy is associated with an increased risk of preterm rupture of membranes, which may occur in up to $12-28 \%$ of cases, and of preterm labor, with about $30.5 \%$ of cases delivering before 32 weeks. $^{6}$

In a small proportion, monochorionic twins treated with laser therapy are complicated with PABS, leading to limb constrictions or amputations, facial cleft and even intrauterine fetal death. In the largest series, the recipient is more frequently affected by PABS. ${ }^{1-4}$ This could be explained by an amniotic fluid excess allowing more fetal movements in the recipient than the donor. In our case, the affected fetus was the donor, perhaps because amniotic fluid was normalized after SLPC.

The exact mechanism for the development of PABS remains unclear, but one plausible explanation is that PABS is consequence to the inadvertent septostomy during the invasive procedure, creating free-floating amniotic sheets, which entrap the fetal parts and umbilical cord. ${ }^{1-6}$ In one series, septostomy was reported 
to occur in $7 \%$ of cases after SLPC and accounted for $50 \%$ of PABS cases. ${ }^{4}$

Another plausible mechanism for the development of PABS is postoperative chorioamniotic membrane separation (CMS), which is common after fetoscopic surgery, occurring in $47 \%$ of cases. ${ }^{1,3}$

Antenatal detection of PABS is challenging and would require a high index of suspicion, particularly when floating membranes suggestive of septostomy or CMS are detected. Pregnancies treated by SFLP for TTTS should raise awareness of PABS and may justify targeted ultrasound surveillance including Doppler studies and three-dimensional sonography.

When PABS is detected, weekly color Doppler examination of the distal part of the affected limb is necessary to detect compromised limb vascularization. ${ }^{1,3}$ Successful fetoscopic release of the amniotic band has been described in cases of impaired blood flow. To date, 19 cases have been published, 58\% having full functional recovery of the constricted limb after delivery. ${ }^{8,9,10}$ Even though it is a rare condition, Obstetricians should be aware of the possibility of PABS in monochorionic twin pregnancies treated by SFLP for TTTS. Serial ultrasound follow-up with Doppler and three-dimensional sonography could contribute to better diagnosis, counseling and potential treatment of cases complicated with PABS.

Funding: No funding sources

Conflict of interest: None declared

Ethical approval: Not Required

\section{REFERENCES}

1. Ting Y, Lao T, Law M, Cheng Y, Lau K, Leung Y. Pseudoamniotic Band Syndrome after In Utero Intervention for Twin-to-Twin Transfusion Syndrome: Case Reports and Literature Review. Fetal Diagn Ther. 2016; 40(1):67-72.

2. Rodrigues A, Araújo C, Carvalho R, Melo M, Pinto L, Mendes da Graça L. Limb constriction secondary to pseudoamniotic band syndrome after selective fetoscopic laser surgery: report of a case with a favorable outcome. Fetal Diagn Ther. 2012;32(4):288-91.

3. Lafitte A, Verspyck E, Pasquier C, Dolly P, Dreyfus M, Benoist G. Pseudoamniotic band syndrome after fetoscopic laser ablation of placental anastomoses for twin-twin transfusion syndrome. two case reports and systematic review. J Ultrasound Med. 2017;36(11):2373-7.

4. Winer N, Salomon L, Essaoui M, Nasr B, Bernard JP. Pseudoamniotic band syndrome: a rare complication of monochorionic twins with fetofetal transfusion syndrome treated by laser coagulation. AJOG. 2008;198(4):393-5.

5. Karunaratne S, Mukkherjee S, Ramanan R. Laser therapy for twin-to-twin transfusion syndrome causing amniotic band syndrome. Arch Dis Fetal Neonatal Ed. 2011;(96):1.

6. Cruz-Martinez R, Mieghem T, Lewi L, Eixarch E, Cobo $\mathrm{T}$, Martinez $\mathrm{J}$, et al. Incidence and clinical implications of early inadvertent septostommy after laser therapy for twin-twin transfusion syndrome. Ultrasound Obstet Gynecol. 2011;37(4):458-62.

7. Habli M, Bombrys A, Lewis D, Lim FY, Polzin W, Maxwell R et al. Incidence of complications in twintwin transfusion syndrome after selective Fetoscopic laser photocoagulation: a single-center experience. Am J Obstet Gynecol. 2009;201(4):417.

8. Derderian S, Iqbal C, Goldstein R, Lee H, Hirose S. Fetoscopic approach to amniotic band syndrome. J Pediat Surg.2014;49(2):359-62.

9. Richter J, Wergeland H, DeKoninck P, Catte L, Deprest L. Fetoscopic Release of an Amniotic Band with Risk of Amputation: Case Report and Review of the Literature. Fetal Diagn Ther. 2012; 31(2):1347.

10. Soldado F, Aguirre M, Peiró JL, Carreras E, Arevalo $\mathrm{S}$, Fontecha $\mathrm{C}$ et al. Fetoscopic Release of Extremity Amniotic Bands with Risk of Amputatio. Pediatr Orthop. 2009;29(3):290-3.

Cite this article as: Cunha SS, Coutada RS, Neiva AR, Ribeiro DC. Fetal Limb amputation secondary to pseudoamniotic band syndrome after selective fetoscopic laser photocoagulation: case report. Int J Reprod Contracept Obstet Gynecol 2018;7:4765-7. 